\title{
Indication for a volatile element 114
}

By R. Eichler ${ }^{1,2, *}$, N. V. Aksenov ${ }^{3}$, Yu. V. Albin ${ }^{3}$, A. V. Belozerov³, G. A. Bozhikov', V. I. Chepigin ${ }^{3}$, S. N. Dmitriev ${ }^{3}$, R. Dressler ${ }^{1}$, H. W. Gäggeler ${ }^{1,2}$, V. A. Gorshkov ${ }^{3}$, R. A. Henderson ${ }^{4}$, A. M. Johnsen ${ }^{4}$, J. M. Kenneally ${ }^{4}$, V. Ya. Lebedev ${ }^{3}$, O. N. Malyshev ${ }^{3}$, K. J. Moody ${ }^{4}$, Yu. Ts. Oganessian ${ }^{3}$, O. V. Petrushkin ${ }^{3}$, D. Piguet ${ }^{1}$, A. G. Popeko ${ }^{3}$, P. Rasmussen ${ }^{1}$,

A. Serov ${ }^{1,2}$, D. A. Shaughnessy ${ }^{4}$, S. V. Shishkin ${ }^{3}$, A. V. Shutov ${ }^{3}$, M. A. Stoyer ${ }^{4}$, N. J. Stoyer ${ }^{4}$, A. I. Svirikhin ${ }^{3}$,

E. E. Tereshatov ${ }^{3}$, G. K. Vostokin ${ }^{3}$, M. Wegrzecki ${ }^{5}$, P. A. Wilk ${ }^{4}$, D. Wittwer ${ }^{2}$ and A. V. Yeremin ${ }^{3}$

${ }^{1}$ Labor für Radio- und Umweltchemie, Paul Scherrer Institut, 5232 Villigen, Switzerland

2 Departement für Chemie und Biochemie, Universität Bern, 3012 Bern, Switzerland

${ }^{3}$ Flerov Laboratory of Nuclear Reactions, Joint Institute for Nuclear Research, 141980 Dubna, Russia

${ }^{4}$ Lawrence Livermore National Laboratory, Livermore, CA 94551, USA

${ }^{5}$ Insitute of Electron Technology, 02-668 Warsaw, Poland

(Received June 30, 2009; accepted in revised form November 2, 2009)

\section{Transactinides / Element 114 / Adsorption / \\ Thermochromatography}

Summary. Recently, the chemical investigation of element 112 revealed a highly volatile, noble metallic behaviour, as expected for the last group 12 member of the periodic table. The observed volatility and chemical inertness were ascribed to the growing influence of relativistic effects on the chemical properties of the heaviest elements with increasing nuclear charge. Here, we report for the first time on gas phase chemical experiments aiming at a determination of element 114 properties. This element was investigated using its isotopes ${ }^{287} 114$ and ${ }^{288} 114$ produced in the nuclear fusion reactions of ${ }^{48} \mathrm{Ca}$ with ${ }^{242} \mathrm{Pu}$ and ${ }^{244} \mathrm{Pu}$, respectively. Identification of three atoms of element 114 in thermochromatography experiments and their deposition pattern on a gold surface indicates that this element is at least as volatile as simultaneously investigated elements $\mathrm{Hg}$, At, and element 112. This behaviour is rather unexpected for a typical metal of group 14.

\section{Introduction}

The enhanced nuclear stability around the closed nuclear shells predicted by microscopic theory [1-3] motivated an extensive experimental quest for elements with $Z \sim 114$. However, searches in nature (for review see [4]) and among the products of fusion reactions or nuclear transfer [5-7] were not successful before 1999. Finally, element 114 was first ever detected at the Flerov Laboratory for Nuclear Reactions (FLNR), Dubna, Russia in 2004, where the formation of the isotopes ${ }^{286-289} 114$ was observed in the nuclear fusion reactions of ${ }^{48} \mathrm{Ca}$ with ${ }^{242,244} \mathrm{Pu}$ (for review see [8]). The observed longer half-lives of up to several seconds indicate an enhanced nuclear stability of these heaviest nuclei. As an important consequence, chemical investigations of element 114 appeared to be feasible. The systematic order of the periodic table places element 114

\footnotetext{
*Author for correspondence (E-mail: robert.eichler@psi.ch).
}

into group 14 together with carbon, silicon, germanium, tin, and lead. The enhancement of the metallic character with increasing atomic number $Z$ is an obvious trend observed along the main groups 13-17 of the periodic table. Thus, a metallic character can be expected for element $114[9,10]$. However, relativistic calculations of the electronic structures of transactinides suggest contraction of the spherical $s$ - and $p_{1 / 2}$-electron orbitals [11-13], thus increasing the chemical stability of the elemental atomic state for element 114 with an electronic ground state configuration of Rn: $5 f^{14} 6 d^{10} 7 s^{2} 7 p_{1 / 2}^{2}$ [11-13]. Therefore, a high volatility and chemical inertness were postulated for this element [14-19]. Modern relativistic calculation methods predict atomic properties for element 114 indicating a higher chemical inertness compared to that of the lighter group 14 metal lead, but still with pronounced metallic properties [15-21]. In this work, we describe experiments which have been conducted to assess these chemical properties of element 114 based on the measurement of its adsorption properties on a gold surface. In general, the thermochromatographic method allows for the most efficient determination of the deposition pattern of single atoms of a volatile species on a chromatographic surface, where a stationary negative temperature gradient is applied. The characteristic interaction potential between the single atomic species and the surface can be quantified from this deposition behaviour [22]. This method is suitable to investigate transactinide elements produced in nuclear reactions on a one-atom-at-a-time basis and was used already for chemical investigations of transactinide elements Rf [23], Db [24], Sg [25], Hs [26], and element $112[27,28]$.

\section{Experimental}

The experiments were performed with the insitu volatilization and on-line detection technique [29] in combination with the cryo-online detector (COLD) [27, 28, 30,31]. The 
products of the heavy ion induced nuclear fusion reaction recoil out of the target, are stopped in a carrier gas, and are subsequently transported through a perfluoroalkoxy (PFA) Teflon capillary into a hot oven $\left(850^{\circ} \mathrm{C}\right)$. The oven contains a quartz wool filter and a small piece of tantalum metal, serving as a trap for aerosol particles, water, oxygen, and other reactive species. Only volatile and chemically inert products pass through this separation step and are further transported to the thermochromatographic detection system COLD described elsewhere [27, 28,31]. Here, species are deposited along the established temperature gradient according to their adsorption interaction with the detector surfaces. COLD was equipped with 32 silicon detector pairs, of which one side was covered by a thin gold layer whereas the opposite side was passivated by a thin layer of $\mathrm{SiO}_{2}$. It was assumed that single atoms of element 114 adsorbed on the Au covered detectors due to the generally stronger interaction observed for almost all elements in the periodic table with gold compared to $\mathrm{SiO}_{2}$. Moreover, the gold covered side is at about $5 \mathrm{~K}$ lower temperature compared to the uncovered side due to the cooling arrangement of the channel. The event-by-event measurement of $\alpha$-decays and spontaneous fission (SF) decays in COLD was analysed as outlined in Fig. 1. This procedure should provide an online identification of single atoms. The same setup was already applied to investigate chemical properties of element $112[27,28]$.

In the first experiment (Experiment a), performed in 2007 at the U-400 cyclotron at FLNR Dubna, element 114 was produced in the nuclear fusion reaction $\left.{ }^{242} \mathrm{Pu}\left({ }^{48} \mathrm{Ca}, 3 n\right)\right)^{287} 114$ $\left(T_{1 / 2} \sim 0.5 \mathrm{~s}, \alpha\right)$ [8]. A stationary grid-supported ${ }^{242} \mathrm{PuO}_{2}$ target $\left(1.4 \mathrm{mg} \mathrm{cm}^{-2}\right.$; the target material was facing the beam) deposited on a thin Ti foil backing $\left(0.7 \mathrm{mg} \mathrm{cm}^{-2}\right)$ was irradiated during $16 \mathrm{~d}$ with an overall beam dose of $3.8 \times 10^{18}$ ${ }^{48} \mathrm{Ca}$ particles at a projectile energy in the target material of 228-246 MeV. This energy was calculated from the beam energy delivered by the accelerator of $273 \pm 3 \mathrm{MeV}$, and energy losses within an entrance window of $1.81 \mathrm{mg} / \mathrm{cm}^{2} \mathrm{Ti}$ and a $5 \mathrm{~mm}$ thick slit of $\mathrm{He} / \mathrm{Ar}(50 \% / 50 \%)$ between the vacuum window and the target using the SRIM code [32]. The target grid transmission was $80 \%$. The gas flow rate in the experiments was $1.51 / \mathrm{min}$. Because the measured mean overall transport time of volatile reaction products was $2.2 \mathrm{~s}$, the ${ }^{287} 114$ isotope is expected to be transported though the 8-m-long PFA Teflon capillary ( $1.56 \mathrm{~mm}$ inner diameter) to the COLD thermochromatography detector with an efficiency of $5 \% .{ }^{283} 112\left(T_{1 / 2} \sim 3.8 \mathrm{~s}, \alpha\right)$ was produced as an $\alpha$-decay product of the primary product ${ }^{287} 114$ and should be transported to COLD with a much higher efficiency of $67 \%$. A temperature gradient from $+32{ }^{\circ} \mathrm{C}$ to $-164{ }^{\circ} \mathrm{C}$ was established in COLD.

The production of ${ }^{288} 114\left(T_{1 / 2} \sim 0.8 \mathrm{~s}, \alpha\right)$ and ${ }^{289} 114$ $\left(T_{1 / 2} \sim 2.6 \mathrm{~s}, \alpha\right)$ has been observed in the nuclear reactions ${ }^{244} \mathrm{Pu}\left({ }^{48} \mathrm{Ca}, 4 n\right)$ and ${ }^{244} \mathrm{Pu}\left({ }^{48} \mathrm{Ca}, 3 n\right)$, respectively [8]. Hence, in a second thermochromatography experiment performed also in 2007 at FLNR Dubna (Experiment b), a ${ }^{244} \mathrm{PuO}_{2}$ target $\left(1.4 \mathrm{mg} \mathrm{cm}^{-2}\right)$ deposited on a Ti backing $\left(0.7 \mathrm{mg} \mathrm{cm}^{-2}\right)$ was irradiated for $17 \mathrm{~d}$ with a beam dose of $4.5 \times 10^{18}$ ${ }^{48} \mathrm{Ca}$. The target setup was identical to the one used in Experiment a. The primary energy of the beam was $278 \pm$ $3 \mathrm{MeV}$. Hence, a projectile energy in the target material of top

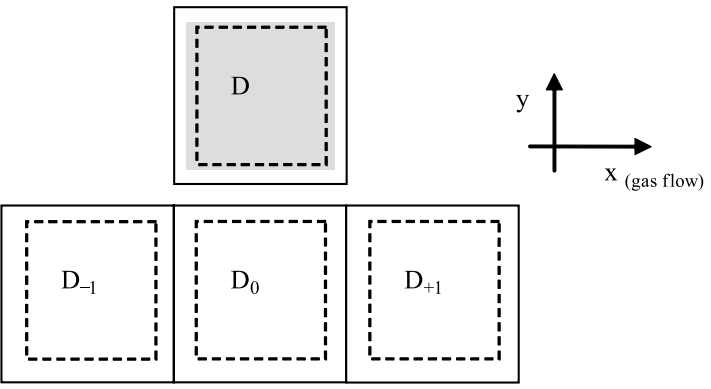

Fig. 1. Schematic section of the open COLD channel. The detectors considered to be reached by the particles emitted due to the alpha and SF decay of an atom adsorbed on a gold covered top detector $\mathrm{D}$ of a detector pair mounted in the detector array COLD. Note, that the gold coverage (light grey) is slightly larger than the active detector surface (inside the dashed-line square). Detector dimensions in the channel were: Gas slit thickness $h=1.52 \mathrm{~mm}$, Detector size: $x=11.30 \mathrm{~mm}, y=11.60 \mathrm{~mm}$, Gold coverage: $x_{\max }=10.6 \mathrm{~mm}$, $y_{\max }=10.6 \mathrm{~mm}$, Active detector surface: $x_{\mathrm{a}}=9.7 \mathrm{~mm}, y_{\mathrm{a}}=9.7 \mathrm{~mm}$. Hence, $83.74 \%$ of the gold surface covers the active detector surface.

233-251 MeV was calculated as explained above. Due to the longer half-lives, the transport efficiencies are $15 \%\left({ }^{288} 114\right)$ and $56 \%\left({ }^{289} 114\right)$, respectively. The temperature range covered within COLD in experiment (b) was established between $+8{ }^{\circ} \mathrm{C}$ and $-170{ }^{\circ} \mathrm{C}$.

In both experiments, ${ }^{185} \mathrm{Hg}$ was produced simultaneously due to a neodymium $\left(50 \mu \mathrm{g} \mathrm{cm}^{-2}\right.$, natural isotopic composition) admixture to the target in the nuclear fusion reaction with ${ }^{48} \mathrm{Ca} .{ }^{219} \mathrm{Rn}$ and isotopes of astatine were also permanently produced in multi-nucleon transfer reactions of the ${ }^{48} \mathrm{Ca}$ beam with ${ }^{242,244} \mathrm{Pu}$ and transported to the COLD. The simultaneous measurements of ${ }^{185} \mathrm{Hg}$ turned out to be very important to determine the retention capability of the detector gold surface. After typically one week, the detector surfaces started to be less able to retain ${ }^{185} \mathrm{Hg}$ quantitatively. At this point it was always decided to replace the detectors and/or to clean their surfaces. To achieve this goal, a washing procedure was applied using methanol, acetone, and diethylether. The origin of the contamination remained unclear, though minor impurities in the Ar carrier gas seem the most likely cause. A water content of $0.1 \mathrm{ppm}$ corresponding to a dew point of water of $-95^{\circ} \mathrm{C}$ was obtained in the carrier gas by the drying components installed in the gas loop consisiting of a $950{ }^{\circ} \mathrm{C} \mathrm{Ta}$ getter and two drying tubes filled with Siccapent. Subsequently the temperature gradient was established with liquid nitrogen. The water content in the carrier gas was permanently monitored using Xentaur HTF sensors. These measurements were in very good agreement with the observed alpha spectroscopic resolution decrease in the detectors where the ice deposition started, as observed also previously [33].

At the expected low count rates the position correlation, i.e. the detection of a decay chain in one detector pair or its neighboring detectors (see Fig. 1) makes the assignments to the decay of single atoms more certain, i.e. with very low probablities for being of random origin. The gold coverage on the top detectors being slightly larger than the active surface makes the non observation of parts of the decay chains possible (see Fig. 1 and Table 1), though. 
Table 1. Detection efficiencies of a species adsorbed on the Au covered detector surface $D$.

\begin{tabular}{|c|c|c|c|c|}
\hline $\begin{array}{l}\text { Decay } \\
\text { type }^{\mathrm{a}}\end{array}$ & $\begin{array}{c}\text { Efficiency } \\
D, D_{0}+D_{-1}+D_{+1} \\
\text { if deposited on } \\
\text { the entire Au } \\
\text { surface }\end{array}$ & $\begin{array}{c}\text { Efficiency } \\
D+D_{0}+D_{-1}+D_{+1} \\
\text { if deposited on } \\
\text { the active } \mathrm{Au} \\
\text { surface }\end{array}$ & $\begin{array}{c}\text { Efficiency } \\
D+D_{0}+D_{-1}+D_{+1} \\
\text { if deposited on } \\
\text { the non-active } \mathrm{Au} \\
\text { surface }\end{array}$ & Efficiency $^{\mathrm{b}}$ \\
\hline$\varepsilon_{\alpha}$ & $71.6 \%$ & $81.6 \%$ & $20.2 \%$ & \\
\hline$\varepsilon_{2 \mathrm{SF}}$ & $52.9 \%$ & $63.2 \%$ & $0 \%$ & \\
\hline$\varepsilon_{1 \mathrm{SF}}$ & $37.4 \%$ & $36.8 \%$ & $40.4 \%$ & \\
\hline$\varepsilon_{\alpha-2 \mathrm{SF}}$ & & $52.1 \%$ & $0 \%$ & $43.6 \%$ \\
\hline$\varepsilon_{\alpha-1 \mathrm{SF}}$ & & $29.5 \%$ & $8.5 \%$ & $26.1 \%$ \\
\hline$\varepsilon_{\alpha-2 \mathrm{SF}}$ & & $43.0 \%$ & $0 \%$ & $36.0 \%$ \\
\hline$\varepsilon_{\alpha-1 \mathrm{SF}}$ & & $23.8 \%$ & $1.8 \%$ & $20.2 \%$ \\
\hline$\varepsilon_{m-\alpha-2 \mathrm{SF}}$ & & $9.0 \%$ & $0 \%$ & $7.5 \%$ \\
\hline$\varepsilon_{m-\alpha-1 \mathrm{SF}}$ & & $5.7 \%$ & $6.6 \%$ & $5.9 \%$ \\
\hline
\end{tabular}

\section{Results}

The search for genetically linked correlated decay chains was performed using the published decay data of the relevant isotopes [8], applying an energy interval of $\pm 0.2 \mathrm{MeV}$ and correlation times $\left(t_{\text {corr }}\right)$ equal to five times the individual half-lives.

In experiment (a) one decay chain was observed (Fig. 2, right side, chain 1), which we attribute to the decay of ${ }^{287} 114$. The number of expected random events during the course of the entire experiment is calculated as $3 \times 10^{-5}$ for the entire decay chain and the number of expected random alpha decays erroneously attributed to ${ }^{287} 114$ preceding a true ${ }^{283} 112$ decay chain within $19 \mathrm{~s}$ is $1.9 \times 10^{-2}$ (see Table A1). The thermochromatographic deposition patterns of ${ }^{185} \mathrm{Hg}$ and ${ }^{219} \mathrm{Rn}$ measured in experiment (a) are depicted in Fig. 3 (panel 1). Additionally, three events of ${ }^{283} 112$ were detected which are described in more detail in [28]. Their deposition pattern is shown in Fig. 3 (panel 2). With respect to the transport efficiency for ${ }^{283} 112\left(T_{1 / 2}=3.8 \mathrm{~s}\right)$ of about $67 \%$, the production of 6 atoms ${ }^{287} 114$ can be estimated. At a transport efficiency for ${ }^{287} 114$ of about $5 \%$ and the given detection efficiencies the expected number of observed ${ }^{287} 114$ would be 0.22 . Therefore, the detection of

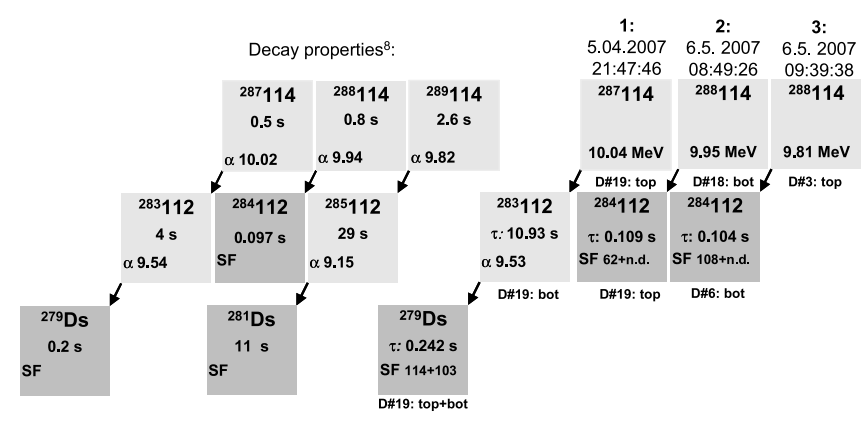

Fig. 2. The decay properties of ${ }^{287-289} 114$ compared with the results of this work. one ${ }^{287} 114$ event is not unlikely. More surprising was the observation of this decay chain on detector 19, held at a temperature of $-88^{\circ} \mathrm{C}$ (Fig. 3, panel 3).

In experiment (b) we observed one additional decay chain, which we assign to the decay of the isotope ${ }^{288} 114$ (s.S. 3) (Fig. 2, right side, chain 2). It was observed on detector 19 held at $-90^{\circ} \mathrm{C}$ (Fig. 3, panel 4) and decaying by $\mathrm{SF}$ into the neighbouring bottom detector 18. Despite a nonzero SF-background of about one SF per $15 \mathrm{~d}$ in each detector the identification of the very short-lived genetically linked $\alpha$-SF-decay chains of ${ }^{288} 114$ with correlation times of less than $0.5 \mathrm{~s}$ is highly significant. The number of expected random events of this type is derived as $1.4 \times 10^{-3}$ (see Table A1). The deposition temperature is very similar to that observed for the first atom. Another interesting event was observed, which we tentatively attribute to the decay of ${ }^{288} 114$ (Fig. 2, right side, chain 3). The $\alpha$-event was measured on detector $3\left(-4{ }^{\circ} \mathrm{C}\right.$ ) (see Fig. 3, panel 4$)$, hence at a temperature significantly higher compared to that measured for the first two atoms. If the nuclear lifetime is comparable to the transport time through the detector array, the probability of decay in-flight becomes significant. At our gas flow rate, the net transport time of the carrier gas through the COLD amounts to about $0.26 \mathrm{~s}$. The correlated SF-decay of the genetically linked ${ }^{284} 112$ was observed 104 ms later three detectors downstream, on detector 6 . The observation that the decay of a daughter atom is displaced from that of the mother atom can be explained by the recoil of the daughter atom out of the detector during the alpha particle emission, followed by a transport with the carrier gas. This effect was previously observed in an almost identical detector device [34]. ${ }^{284} 112$ has an $-\Delta H_{\mathrm{ads}}^{\mathrm{Au}}(112)=52 \mathrm{~kJ} / \mathrm{mol}[27,28]$ leading to a considerable retention at the temperatures established between detector $4\left(-4{ }^{\circ} \mathrm{C}\right)$ and detector $6\left(-19^{\circ} \mathrm{C}\right)$. Therefore, it can be assumed, that ${ }^{284} 112$ was most probably adsorbed during its decay. The number of expected random events of this type is calculated as $1.1 \times 10^{-2}$ (see Table A1). Decay chains related to the isotope ${ }^{289} 114$ could 


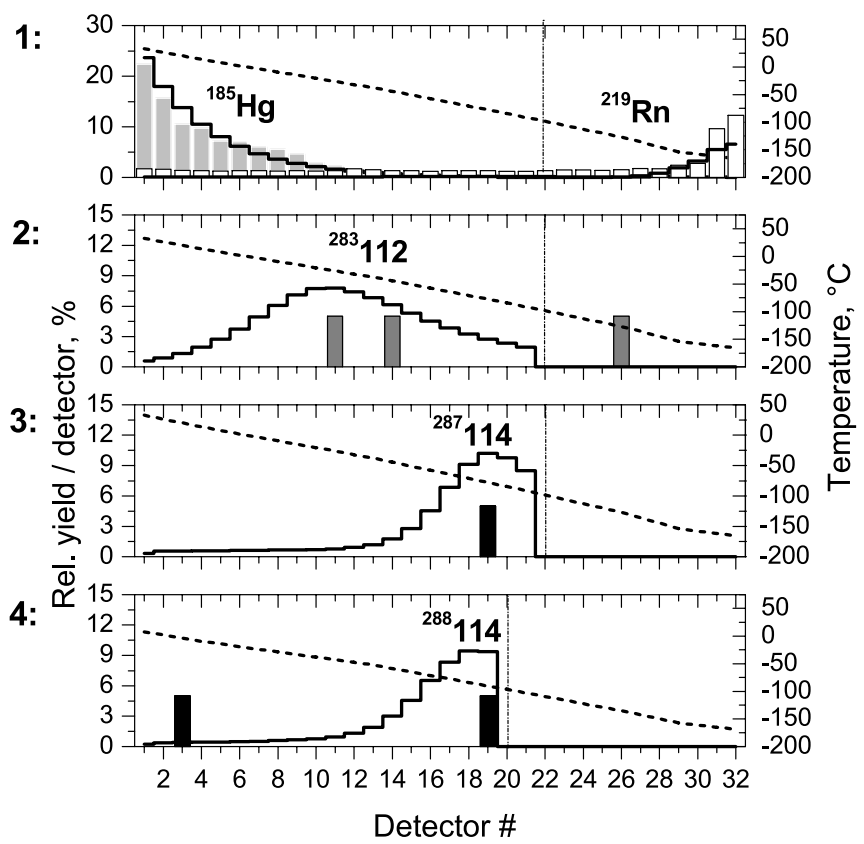

Fig. 3. The thermochromatographic deposition patterns of mercury, radon, elements 112 and 114 in the COLD from experiments (a) and (b). The dashed line (right handed axis) indicates the temperature gradient established during the experiments. Panels 1-3 are observations from experiment (a). Panel 1: The deposition of ${ }^{185} \mathrm{Hg}\left(T_{1 / 2}=49 \mathrm{~s}\right.$; light grey bars) and ${ }^{219} \mathrm{Rn}\left(T_{1 / 2}=4 \mathrm{~s}\right.$; white bars) are shown. Panel 2: The deposition of the observed atoms of ${ }^{283} 112$ (dark grey bars) are depicted [28]. Panel 3: The deposition position of ${ }^{287} 114$ is given. In Panel 4 the deposition position of the two atoms assigned to ${ }^{288} 114$ observed in experiment (b) are shown. Most probable relative yield distributions of these elements as a function of the detector number as expected by a microscopic model of the adsorption chromatographic process based on a Monte Carlo approach [22] are included as solid black lines (left handed axis): For ${ }^{185} \mathrm{Hg}, \mathrm{a}-\Delta H_{\mathrm{ads}}^{\mathrm{Au}} \geq 50 \mathrm{~kJ} / \mathrm{mol}$ is derived in good agreement with $-\Delta H_{\mathrm{ads}}^{\mathrm{Au}}(\mathrm{Hg})=98 \mathrm{~kJ} / \mathrm{mol}$ [31]; for ${ }^{219} \mathrm{Rn},-\Delta H_{\text {ads }}^{\text {ice }}$ was determined as $19 \mathrm{~kJ} / \mathrm{mol}$, in good agreement with the $-\Delta H_{\text {ads }}^{\text {ice }}(\mathrm{Rn})=20 \mathrm{~kJ} / \mathrm{mol}$ [35]. As it was shown in [28] the behavior of ${ }^{283} 112$ was consisitent with previous measurements from [27] yielding $-\Delta H_{\text {ads }}^{\mathrm{Au}}(112)=52 \mathrm{~kJ} / \mathrm{mol}$. For ${ }^{287-288} 114$ the most probable adsorption enthalpy $-\Delta H_{\text {ads }}^{\text {Au }}(\mathrm{E} 114)=34 \mathrm{~kJ} / \mathrm{mol}$ was derived (see Appendix). The vertical dashed-dotted lines indicate the assumed onset of ice formation on the gold surfaces deduced form the dew point of $-95^{\circ} \mathrm{C}$ in the carrier gas. About 10 and $40 \%$ of ${ }^{283} 112$ and ${ }^{287,288} 114$, respectively, are expected to reach the ice covered detectors. However the simulations do not show the expected deposititon of ${ }^{283} 112$ and ${ }^{287,288} 114$ on the ice covered detectors, since no adsorption enthalpies on ice surfaces are known for these elements.

not be identified unambiguously due to the two longer-lived descendants ${ }^{285} 112\left(T_{1 / 2} \sim 29 \mathrm{~s}, \alpha\right)$ and ${ }^{281}$ Ds $\left(T_{1 / 2} \sim 11 \mathrm{~s}\right.$, $\mathrm{SF})$. In this case the expected number of random events during the entire experiment of 27 indicates a high probality to obtain random correlation chains (see Table A1).

From the observation of three atoms of element 114 adsorbed on gold surfaces of the COLD detector, we determined its most probable standard adsorption enthalpy on gold as $-\Delta H_{\text {ads }}^{\mathrm{Au}}(\mathrm{E} 114)=34_{-3}^{+20} \mathrm{~kJ} / \mathrm{mol}(68 \%$ credibility interval) (see Appendix).

\section{Discussion}

The chemical state of element 114 formed in an extremely clean and dry noble gas flow and passing an $800{ }^{\circ} \mathrm{C}$ hot oven with metallic tantalum getter material inside is most probably the elemental one. The reactivity of element 114 is according to theoretical calculations low. It does not react with $\mathrm{O}_{2}$ to form $114 \mathrm{O}$ [21]. It will also not react with $\mathrm{Cl}_{2}$ to form $114 \mathrm{Cl}_{2}$. It might react with $\mathrm{F}_{2}$ (see [13-15]). $\mathrm{Pb}$ is similarly to $\mathrm{Hg}$ known to form volatile methyl and ethyl compounds. All the possible compounds of element 114 mentioned above would be destroyed by the hot tantalum getter, especially since they are supposed to be less stable than the corresponding lead compounds [36]. If there are chemically reactive components in the carrier gas, they are expected to react with the simultaneously measured $\mathrm{Hg}$. An efficient aerosol particle transport is unlikely since enormous amounts of nuclides from non volatile elements produced in nuclear transfer reactions would have been detected. From all data shown in Fig. 3 we conclude that the observed deposition patterns of elemental mercury, radon, and of element 112 agree very well with published data $[27,31,35]$. Based on this internal calibration, we conclude that the three decay chains we attribute to the decay of element 114 truly reflect its chemical behaviour.

The observation of element 114, transported at room temperature through our experimental setup to the COLD apparatus, points to a volatility being at least as high as that of $\mathrm{Hg}$, At, and element 112. Therefore, our experimental result indicates a substantially increased stability of the atomic state of element 114 compared to its lighter metallic homologue in group 14-lead.

Recent relativistic density functional calculations predict the formation of metallic bonds between element 114 and surfaces of transition metals [20]. The estimated $-\Delta H_{\mathrm{ads}}^{\mathrm{Au}}(\mathrm{E} 114)=92 \mathrm{~kJ} / \mathrm{mol}$ would correspond to a deposition temperature of element 114 on gold of about $+150{ }^{\circ} \mathrm{C}$ under our experimental conditions. A semi-empirical macroscopic metal-metal adsorption model [37] predicts an even higher adsorption enthalpy of a metal-like element 114 on gold of $-\Delta H_{\mathrm{ads}}^{\mathrm{Au}}(\mathrm{E} 114)=183 \mathrm{~kJ} / \mathrm{mol}$ [38]. On the other hand, the adsorption enthalpy of an assumed noble gas-like element 114 on gold surfaces was estimated as $-\Delta H_{\mathrm{ads}}^{\mathrm{Au}}(\mathrm{E} 114)=42 \pm 5 \mathrm{~kJ} / \mathrm{mol}$ [39]. The comparison between these predictions and our experimental result of $-\Delta H_{\mathrm{ads}}^{\mathrm{Au}}(\mathrm{E} 114)=34_{-11}^{+54} \mathrm{~kJ} / \mathrm{mol}(95 \%$ c.i.) suggests the formation of a weak physisorption bond between atomic 114 and a gold surface. Lead, as the most volatile element of group 14, deposits on gold at temperatures between $800-1000{ }^{\circ} \mathrm{C}[40,41]$ about $1000{ }^{\circ} \mathrm{C}$ higher compared to the deposition of the three atoms that we ascribe to element 114 . Certainly, the deduced adsorption enthalpy of element 114 on gold needs further confirmation.

Acknowledgment. We thank the staff of the U-400 cyclotron for providing intense beams of ${ }^{48} \mathrm{Ca}$. The ${ }^{242} \mathrm{Pu}$ target material was provided by RFNC-VNIIEF, Sarov, Russia. The ${ }^{244} \mathrm{Pu}$ target material was provided by the U.S. DOE through ORNL, Oak Ridge, USA. The LLNL work was performed under the auspices of the U.S. Department of Energy by Lawrence Livermore National Laboratory (contract: DEAC52-07NA27344). This work was supported in part by the Russian Foundation for Basic Research (grant: 07-03-00430-a) and by the Swiss National Science Foundation (grant: 200020-117671/1). 
Table A1. Expected number of random correlations for the various expected types of decay chains $\left(N_{\mathrm{R}}\right)$ and the observed number $\left(N_{\mathrm{obs}}\right)$.

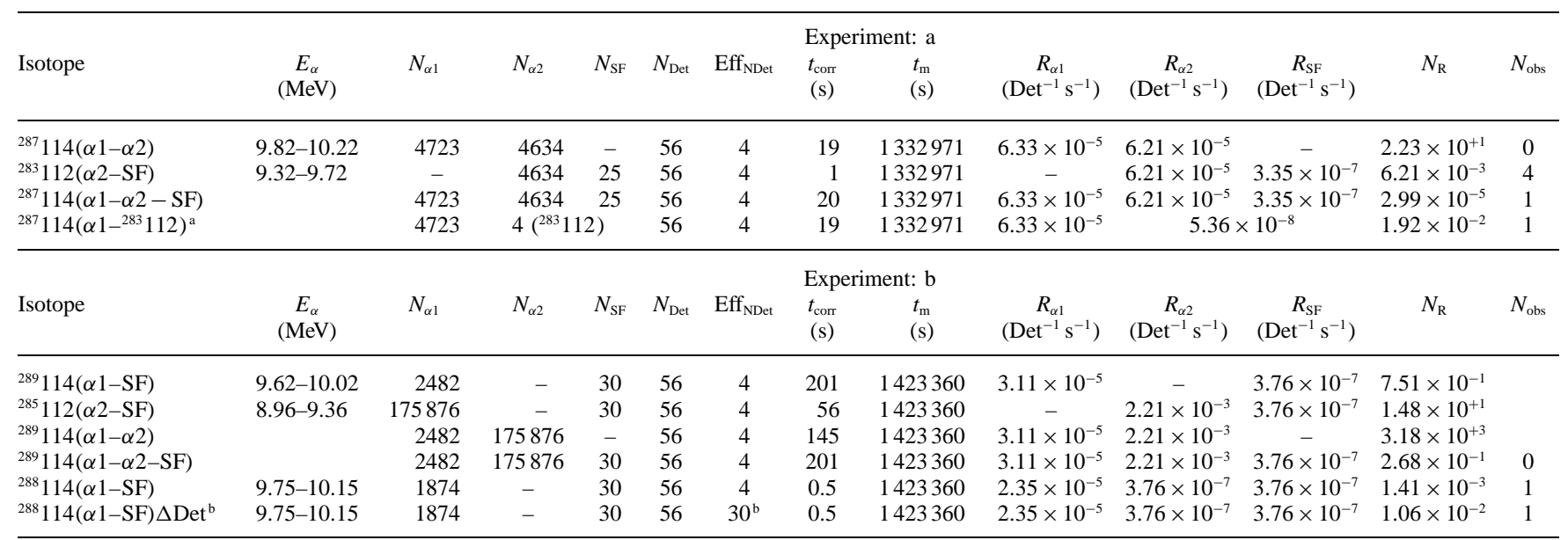

a: The number of expected alpha decays randomly preceding a true correlated ${ }^{283} 112$ decay within $19 \mathrm{~s}$;

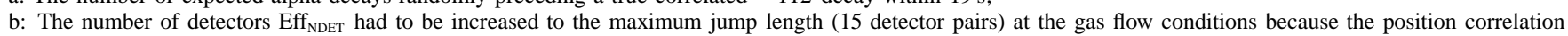
was lost in chain 3 .

\section{Appendix}

\section{A.1 Random probabilities}

The applied chemical separation procedure is not suitable to separate the noble gas radon from the other volatile products. Therefore, the large amounts of various radon isotopes, produced in multi-nucleon transfer reactions of the actinide target atoms with the calcium beam, pass through the thermochromatography column and decay partly inflight in every detector sandwich. Due to the transport of ${ }^{220} \mathrm{Rn}$ a high energy background between $8.5 \mathrm{MeV}$ and 10.0 MeV originating from its non-volatile descendants ${ }^{212} \mathrm{Bi} /{ }^{212} \mathrm{Po}$ is measured. In the deposition zone of radon the detection of a correlated decay chain attributed to a transactinide was impossible to measure. Therefore, the data from detectors 29 to 32 were not included in the data analysis. This leads to a number of detectors considered $\left(N_{\text {Det }}\right)$ of 56 . Another drawback was a short failure of the aerosol particle filter unit behind the recoil chamber. Thus, tiny amounts of long-lived actinides (e.g. ${ }^{242} \mathrm{Pu},{ }^{248} \mathrm{Cm},{ }^{252} \mathrm{Cf}$ ) lead to a spontaneous fission (SF) background of about $1 \mathrm{SF} / \mathrm{d}$ measured in the entire detector during the experiment which was also observed in a 2 month background measurement performed after the experiment. 25 and 30 SF decays were detected throughout the entire experiments (a) and (b), respectively. The rates of the interesting alpha events and SF decays were calculated as:

$$
R_{\alpha i}=\frac{N_{\alpha i}}{t_{\mathrm{m}} N_{\text {Det }}} \quad R_{\mathrm{SF}}=\frac{N_{\mathrm{SF}}}{t_{\mathrm{m}} N_{\text {Det }}}
$$

with: $R_{\alpha i}, R_{\mathrm{SF}}$ - rates of the alpha events and SF events per detector and second throughout the entire experiment; $N_{\text {Det }}-$ number of detectors considered for the data evaluation; $N_{\alpha i}$, $N_{\mathrm{SF}}$ - number of observed alphas or SF in the energy region in the detectors $N_{\text {Det }}$; and $t_{\mathrm{m}}$-duration of the experiment.

The number of expected random events have been calculated assuming an even distribution of interesting alphas and SF in the $N_{\text {Det }}$ detectors [42] (see e.g. $N_{\mathrm{R}}$ for $\alpha$-SF correlation, Eq. (A.2)). The results are compiled in Table A1.

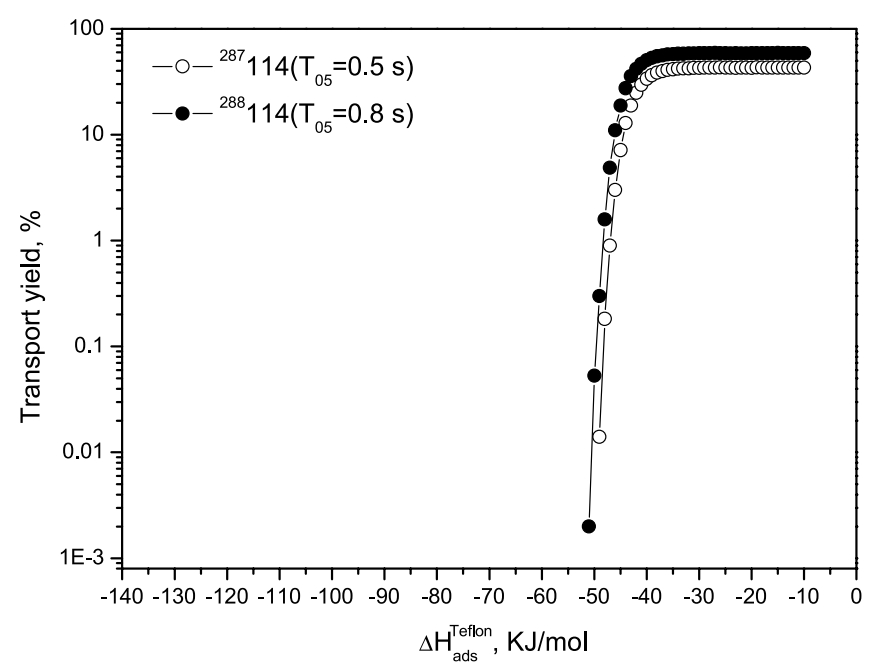

Fig. A1. The transport yield of ${ }^{287} 114$ (filled black circles) and ${ }^{288} 114$ (open circles) through an $8 \mathrm{~m}$ long Teflon capillary with $1.56 \mathrm{~mm}$ inner diameter at a carrier gas flow of $1.51 \mathrm{~min}^{-1}$ held at $25^{\circ} \mathrm{C}$ as a function of the adsorption enthalpy of element 114 on the inert Teflon surface.

$$
N_{R(\alpha-\mathrm{SF})}=R_{\alpha i} N_{\text {Det }} t_{\mathrm{m}} R_{\mathrm{SF}} N_{\text {Det }} t_{\mathrm{corr}} \mathrm{Eff}_{\mathrm{NDet}}
$$

with: Eff $_{\mathrm{NDet}}-$ number of detectors accepted as possible reachable directly by emitted particles (SF-fragment or $\alpha$ ) or due to recoil position displacements (chain 3 ); $t_{\text {corr }}-$ correlation times equal to five times the half-lives (decay data of the relevant isotopes from [8]); and $N_{\mathrm{R}}$ - expected number of random correlations of the given type throughout the entire experiment.

\section{A.2 The statistical analysis of adsorption properties of element 114 on teflon and gold using the Monte-Carlo simulation method}

In the statistical analysis, all events observed were treated equally. The chemical state was assumed to be the elemental one. A kinetic Monte-Carlo based model of gas adsorption thermochromatography [22] assesses the adsorption en- 


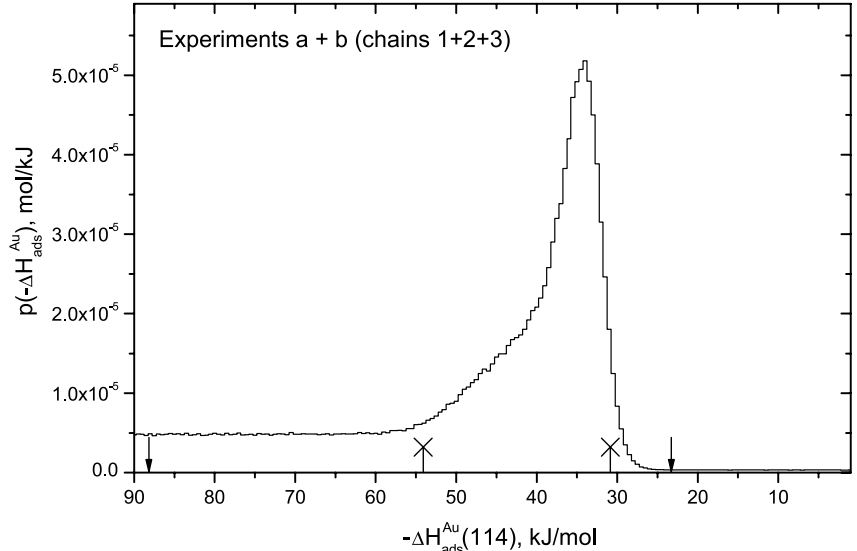

Fig. A2. Joint probability densities to reproduce the observation of element 114 atoms in COLD during the experiments as a function of the only variable parameter - the adsorption enthalpy of element 114 on gold, $\Delta H_{\text {ads }}^{\mathrm{Au}}(\mathrm{E} 114)$. From the maximum of the probability distributions the most likely value of $-\Delta H_{\mathrm{ads}}^{\mathrm{Au}}(\mathrm{E} 114)$ was determined as $34 \mathrm{~kJ} / \mathrm{mol}$. For the error analysis, the corresponding credibility intervals of the probability density distributions were calculated. The black arrows and the black crosses indicate the 95 and $68 \%$ credibility interval, respectively.

thalpy $\left(-\Delta H_{\mathrm{ads}}^{\mathrm{Au}}\right)$ from the observed deposition of element 114 on the gold surface in the COLD (Fig. 2, panels 3 and 4 , solid black lines) under the applied experimental conditions. All atoms of element 114 had to pass through $8 \mathrm{~m}$ of Teflon capillary (inner diameter $1.56 \mathrm{~mm}$ ) at room temperature prior to enter the detector. This limits the adsorption interaction of element 114 on Teflon to $-\Delta H_{\text {ads }}^{\text {Teflon }}<$ $45 \mathrm{~kJ} / \mathrm{mol}$. This limit was deduced using the Monte-Carlo simulation of gas chromatography (Fig. A1). Applying the well established correlations of the microscopic adsorption enthalpies of elements on inert surfaces such as quartz or Teflon [43] one can estimate a conservative upper limit of a sublimation enthalpy $\left(\Delta H_{\text {subl }}\right)$ at which a species is able to pass the Teflon capillary as $63 \mathrm{~kJ} / \mathrm{mol}$. This sublimation enthalpy limit converts empirically to the upper limit adsorption enthalpy on gold $-\Delta H_{\text {ads }}^{\mathrm{Au}}(114) \leq 90 \mathrm{~kJ} / \mathrm{mol}$ [44]. Therefore, we conclude that an adsorption enthalpy of an element on gold larger than $90 \mathrm{~kJ} / \mathrm{mol}$ would lead to non transport of this element from the production site to the detector. These adsorption limits represent indeed a chemical property of element 114 deduced just from the observation of any event related to element 114 in the COLD detector.

Accordingly, the entire statistical analysis of the observations of element 114 adsorption on gold surfaces was performed using an adsorption enthalpy interval $\left(-\Delta H_{\mathrm{ads}}^{\mathrm{Au}}\right)$ between 1 and $90 \mathrm{~kJ} / \mathrm{mol}$.

The simulation of a gas phase transport and surface adsorption through COLD was repeated 10 million times with single atoms of ${ }^{287} 114$ and ${ }^{288} 114$ giving them a certain adsorption enthalpy on gold (which is the only variable in the simulation). From these calculated deposition distributions, the probabilities to obtain the measured distribution of element 114 along the COLD at the applied experimental conditions were derived as a function of the adsorption enthalpy (Fig. A2). The resulting adsorption enthalpy of element 114 on $\mathrm{Au}$ is $-\Delta H_{\mathrm{ads}}^{\mathrm{Au}}(\mathrm{E} 114)=34_{-11}^{+54} \mathrm{~kJ} / \mathrm{mol}(95 \%$ credibility interval).

\section{References}

1. Myers, W. D., Swiatecki, W. J.: Nuclear masses and deformations. Nucl. Phys. 81, 1-60 (1966).

2. Meldner, H.: Predictions of new magic regions and masses for super-heavy nuclei from calculations with realistic shell model single particle Hamiltonians. Ark. Fys. 36, 593-598 (1967).

3. Sobiczewski, A., Pomorski, K.: Description of structure and properties of superheavy nuclei. Prog. Part. Nucl. Phys. 58, 292-349 (2007).

4. Herrmann, G.: Historical reminiscences. In: The Chemistry of Superheavy Elements. (Schädel, M., ed.) Kluwer Academic Publishers, Dordrecht (2003), Chapt. 8, pp. 291-316.

5. Oganessian, Yu. Ts., Utyonkov, V. K., Lobanov, Yu. V., Abdullin, F. Sh., Polyakov, A. N., Shirokovsky, I. V., Tsyganov, Yu. S., Gulbekian, G. G., Bogomolov, S. L., Gikal, B. N., Iliev, S., Subbotin, V. G., Sikhov, A. M., Voinov, A. A., Buklanov, G. V., Subotic, K., Zagrebaev, V. I., Itkis, M. G., Patin, J. B., Moody, K. J., Wild, J. F., Stoyer, M. A., Stoyer, N. J., Shaughnessy, D. A., Kenneally, J. M., Wilk, P. A., Lougheed, R. W., Il'kaeev, R. I., Vesnovskii, S. P.: Experiments to produce isotopes of superheavy elements with atomic numbers $114-116$ in ${ }^{48} \mathrm{Ca}$ ion reactions. Nucl. Phys. A 294, 213-224 (1978).

6. Armbruster, P., Agarwal, Y. K., Brüchle, W., Brügger, M., Dufour, J. P., Gäggeler, H. W., Hessberger, F. P., Hofmann, S., Lemmertz, P., Münzenberg, G., Poppensieker, K., Reisdorf, W., Schädel, M., Schmidt, K. H., Schneider, J. H. R., Schneider, W. F. W, Sümmerer, K., Vermeulen, D., Wirth, G., Ghiorso, A., Gregorich, K. E., Lee, D., Leino, M., Moody, K. J., Seaborg, G. T., Welch, R. B., Wilmarth, P., Yashita, S., Frink, C., Greulich, N., Herrmann, G., Hickmann, U., Hildebrand, N., Kratz, J. V., Trautmann, N., Fowler, M. M., Hoffman, D. C., Daniels, W. R., von Gunten, H. R., Dornhöfer, H.: Attempts to produce superheavy elements by fusion of ${ }^{48} \mathrm{Ca}$ with ${ }^{248} \mathrm{Cm}$ in the bombarding energy range of 4.5-5.2 MeV/u. Phys. Rev. Lett. 54, 406-409 (1985).

7. Gäggeler, H. W., Trautmann, N., Brüchle, W., Herrmann, G., Kratz, J. V., Peuser, P., Schädel, M., Tittel, G., Wirth, G., Ahrens, H., Folger, H., Franz, G., Sümmerer, K., Zendel, M.: Search for superheavy elements in the ${ }^{238} \mathrm{U}+{ }^{238} \mathrm{U}$ reaction. Phys. Rev. Lett. 45, 1824-1827 (1980).

8. Oganessian, Yu. Ts.: Heaviest nuclei from ${ }^{48} \mathrm{Ca}$-induced reactions. J. Phys. G 34, R165-R242 (2007).

9. Eichler, B. Volatility properties of transactinides around $Z=114$ (prediction). Kernenergie 19, 307-311 (1976).

10. Eichler, B.: Volatilization properties of transactinides from metal surfaces and melts (thermochemical calculation). In: PSI Report 03-01, Villigen (2002), ISSN 1019-0643.

11. Fricke, B.: Superheavy elements. Struct. Bond. 21, 90-144 (1975).

12. Pyykkö, P., Desclaux, J.-P.: Relativity and the periodic system of elements. Acc. Chem. Res. 12, 276-281 (1979).

13. Schwerdtfeger, P., Seth, M.: Relativistic effects of the superheavy elements. In: Encyclopaedia of Computational Chemistry. Wiley, New York (1998), Vol. 4, pp. 2480-2499.

14. Pitzer, K. S.: Are elements 112, 114, and 118 relatively inert gases? J. Chem. Phys. 63(2), 1032 (1975).

15. Nash, C. S.: Atomic and molecular properties of elements 112, 114, and 118. J. Phys. Chem. A 109, 3493-3500 (2005).

16. Landau, A., Eliav, E., Ishikawa, Y., Kaldor, U.: Electronic structure of Eka-lead (element 114) compared with lead. J. Chem. Phys. 114, 2977-2980 (2001).

17. Liu, W., van Wüllen, C., Han, Y. K., Choi, Y. J., Lee, Y. S.: Spectroscopic constants of Pb and Eka-lead compounds: comparison of different approaches. Adv. Quant. Chem. 39, 325 $-\overline{355}$ (2001).

18. Seth, M., Faegri, K., Schwerdtfeger, P.: The stability of the oxidation state +4 in group 14 compounds from carbon to element 114 . Angew. Chem. Int. Ed. 37, 2493-2496 (1998).

19. Keller, O. L., Burnett, J. L., Carlson, T. A., Nestor, C. W.: Predicted properties of the super heavy elements. I. Elements 113 and 114, Eka-thallium and Eka-lead. J. Phys. Chem. 74(5), 1127-1134 (1970).

20. Pershina, V., Anton, J., Fricke, B.: Intermetallic compounds of the heaviest elements and their homologs: The electronic structure and bonding of $\mathrm{MM}^{\prime}$, where $\mathrm{M}=\mathrm{Ge}, \mathrm{Sn}, \mathrm{Pb}$ and element 114 , and 
$\mathrm{M}^{\prime}=\mathrm{Ni}, \mathrm{Pd}, \mathrm{Pt}, \mathrm{Cu}, \mathrm{Ag}, \mathrm{Au}, \mathrm{Sn}, \mathrm{Pb}$, and element 114. J. Chem. Phys. 127, 134310 (2007).

21. Pershina, V. P., Borschevsky, A., Eliav, E., Kaldor, U.: Adsorption of elements 112 and 114 on inert surfaces. J. Chem. Phys. 128, 024707 (2008).

22. Zvara, I.: Simulation of thermochromatographic processes by the Monte Carlo method. Radiochim. Acta 38, 95-101 (1985).

23. Zvara, I., Belov, V. Z., Chelnokov, L. P., Domanov, V. P., Hussonnois, M., Korotkin, J. S., Szegolev, B. A., Shalajevski, M. P.: Chemical separation of kurchatovium. Inorg. Nucl. Chem. Lett. 7, 1109-1116 (1971).

24. Zvara, I., Belov, V. Z., Domanov, B. P., Shalajevski, M. P.: Chemical isolation of nielsbohrium as ekatantalum in the form of the anhydrous bromide. Radiokhimya 18, 371-377 (1976).

25. Timokhin, S. N., Yakushev, A. B., Honggui, Xu, Perelygin, V. P., Zvara, I.: Chemical identification of element 106 by thermochromatography. J. Radioanal. Nucl. Chem. Lett. 212, 31-34 (1996)

26. Düllmann, Ch. E., Dressler, R., Eichler, B., Gäggeler, H. W., Glaus, F., Jost, D. T., Piguet, D., Soverna, S., Türler, A., Brüchle, W., Eichler, R., Jäger, E., Pershina, V., Schädel, M., Schausten, B., Schimpf, E., Schött, H.-J., Wirth, G., Eberhardt, K., Thörle, P., Trautmann, N., Ginter, T. N., Gregorich, K. E., Hoffman, D. C., Kirbach, U. W., Lee, D. M., Nitsche, H., Patin, J. B., Sudowe, R., Zielinski, P. M., Timokhin, S. N., Yakushev, A. B., Vahle, A., Qin, Z.: Chemical investigation of hassium (element 108). Nature 418, 859-862 (2002).

27. Eichler, R., Aksenov, N. V., Belozerov, A. V., Bozhikov, G. A., Chepigin, V. I., Dressler, R., Dmitriev, S. N., Gäggeler, H. G., Gorshkov, V. A., Haenssler, F., Itkis, M. G., Lebedev, V. Y., Laube, A., Malyshev, O. N., Oganessian, Yu. Ts., Petruschkin, O. V., Piguet, D., Rasmussen, P., Shishkin, S. V., Shutov, A. V., Svirikhin, A. I., Tereshatov, E. E., Vostokin, G. K., Wegrzecki, M., Yeremin, A. V.: Chemical properties of element 112 . Nature 447, 72-75 (2007).

28. Eichler, R., Aksenov, N. V., Belozerov, A. V., Bozhikov, G. A., Chepigin, V. I., Dressler, R., Dmitriev, S. N., Gäggeler, H. G., Gorshkov, V. A., Haenssler, F., Itkis, M. G., Lebedev, V. Y., Laube, A., Malyshev, O. N., Oganessian, Yu. Ts., Petruschkin, O. V., Piguet, D., Rasmussen, P., Serov, A. A., Shishkin, S. V., Shutov, A. V., Svirikhin, A. I., Tereshatov, E. E., Vostokin, G. K., Wegrzecki, M., Yeremin, A. V.: Thermochemical and physical properties of element 112. Angew. Chem. Int. Ed. 47(17), 3262-3266 (2008)

29. Düllmann, Ch. E., Eichler, B., Eichler, R., Gäggeler, H. W., Jost, D. T., Piguet, D., Türler, A.: IVO, a device for in situ volatilization and on-line detection of products from heavy ion reactions. Nucl. Instr. and Meth. A 479, 631 (2002).

30. Kirbach, U. W., Folden III, C. M., Ginter, T. N., Gregorich, K. E., Lee, D. M., Ninov, V., Omtvedt, J. P., Patin, J. B., Seward, N. K., Strellis, D. A., Sudowe, R., Türler, A., Wilk, P. A., Zielinski, P. M., Hoffmann, D. C., Nitsche, H.: The Cryo-Thermochromatographic Separator (CTS): A new rapid separation and $\alpha$-detection system for on-line chemical studies of highly volatile osmium and hassium $(Z=108)$ tetroxides. Nucl. Instrum. Methods A 484, 587 (2002).
31. Soverna, S., Dressler, R., Düllmann, Ch. E., Eichler, B., Eichler, R., Gäggeler, H. W., Haenssler, F., Niklaus, J.-P., Piguet, D., Qin, Z., Türler, A., Yakushev, A. B.: Thermochromatographic studies of mercury and radon on transition metal surfaces. Radiochim. Acta 93, 1-8 (2005).

32. Ziegler, J. F.: SRIM 2003. Nucl. Instrum. Methods B 219-220, 1027-1036 (2004).

33. Eichler, R., Brüchle, W., Buda, R., Bürger, S., Dressler, R., Düllmann, Ch. E., Dvorak, J., Eberhardt, K., Eichler, B., Folden III, C. M., Gäggeler, H. W., Gregorich, K. E., Haenssler, F., Hoffman, D. C., Hummrich, H., Jäger, E., Kratz, J. V., Kuczewski, B., Liebe, D., Nayak, D., Nitsche, H., Piguet, D., Qin, Z., Rieth, U., Schädel, M., Schausten, B., Schimpf, E., Semchenkov, A., Soverna, S., Sudowe, R., Trautmann, N., Thörle, P., Türler, A., Wierczinski, B., Wiehl, N., Wilk, P. A., Wirth, G., Yakushev, A. B., von Zweidorf, A.: Attempts to chemically investigate element 112 . Radiochim. Acta 94, 181 (2006).

34. Dvorak, J., Brüchle, W., Chelnokov, M., Düllmann, Ch. E., Dvorakova, Z., Eberhardt, K., Jäger, E., Krücken, R., Kuznetsov, A., Nagame, Y., Nebel, F., Nishio, K., Perego, R., Qin, Z., Schädel, M., Schausten, B., Schimpf, E., Schuber, R., Semchenkov, A., Thörle, P., Türler, A., Wegrzecki, M., Wierczinski, B., Yakushev, A., Yeremin, A.: Observation of the $3 n$ evaporation channel in the complete hot-fusion reaction ${ }^{26} \mathrm{Mg}+{ }^{248} \mathrm{Cm}$ leading to the new superheavy nuclide ${ }^{271}$ Hs. Phys. Rev. Lett. 100, 132503 (2008).

35. Eichler, B., Zimmermann, P., Gäggeler, H. W.: Adsorption of radon on ice surfaces. J. Phys. Chem. A 104, 3126-3131 (2000).

36. Hoffmann, P.: Vorraussage von Eigenschaften der Alkylverbindungen der Elemente 112, 114, Astat und 117. Radiochim. Acta 19(3), 69-75 (1973).

37. Eichler, B., Rossbach, H.: Adsorption of volatile metals on metal surfaces and its application in nuclear chemistry. I. Calculation of adsorption enthalpies for hypothetical superheavy elements with $Z$ around 114. Radiochim. Acta 33, 121-125 (1983).

38. Eichler, B.: Metal chemistry of transactinides. PSI Report 00-09, Villigen (2000), ISSN 1019-0643.

39. Eichler, R., Schädel, M.: Adsorption of radon on metal surfaces: a model study for chemical investigations of elements 112 and 114. J. Phys. Chem. B 106, 5413-5420 (2002).

40. Eichler, B.: Dubna Report JINR P12-6662 (1972).

41. Haenssler, F., Eichler, R., Gäggeler, H. W., Soverna, S., Dressler, R., Piguet, D., König, S., Eyholzer, Ch.: Thermochromatographic studies of ${ }^{212} \mathrm{~Pb}$ on metal surfaces. In: PSI Annual Report 2005 (2006) p. 3.

42. Schmidt, K. H., Clerc, H. G., Pielenz, K., Sahm, C. C.: Some remarks on error analysis in the case of pure statistics. Z. Phys. A 316, 19-26 (1984).

43. Eichler, B., Eichler, R.: Gas-phase adsorption chromatographic determination of thermochemical data and empirical methods for their estimation. In: The Chemistry of Superheavy Elements. (Schädel, M., ed.) Kluwer Academic Publishers, Dordrecht (2003), Chap. 6, p. 205.

44. Eichler, R.: Empirical relation between the adsorption properties of elements on gold surfaces and their volatility. Radiochim. Acta 93, 245-248 (2005). 